\title{
Pilot Randomized Clinical Trial of an SSRI vs Bupropion: Effects on Suicidal Behavior, Ideation, and Mood in Major Depression
}

\author{
Michael F Grunebaum*,', Steven P Ellis', Naihua Duan', Ainsley K Burke', Maria A Oquendo' \\ and J John Mann'
}

'Department of Psychiatry, Columbia University and New York State Psychiatric Institute, New York, NY, USA

\begin{abstract}
Randomized controlled trials in depressed patients selected for elevated suicidal risk are rare. The resultant lack of data leaves uncertainty about treatment in this population. This study compared a serotonin reuptake inhibitor with a noradrenergic/dopaminergic antidepressant in major depression with elevated suicidal risk factors. We conducted a double-blind, randomized, clinical pilot trial of paroxetine $(N=36)$ or bupropion $(N=38)$ in DSM IV major depression with a suicide attempt history or current suicidal ideation. The effects during acute ( 8 weeks) and continuation treatment (up to 16 weeks) were measured. Main outcomes were suicidal behavior and ideation. The secondary outcome was modified 17-item Hamilton Depression Rating Scale score subtracting the suicide item (mHDRS-17). Treatment was not associated with time to a suicidal event and no treatment main effect or treatment $\times$ time interaction on suicidal ideation or mHDRS- 17 was found. Exploratory model selection showed modest advantages for paroxetine on: ( 1 ) mHDRS17 ( $p=0.02)$; and (2) in a separate model adjusted for baseline depression, for suicidal ideation measured with the Beck Scale for Suicidal Ideation $(p=0.03)$, with benefit increasing with baseline severity. Depressed patients with greater baseline suicidal ideation treated with paroxetine compared with bupropion appeared to experience greater acute improvement in suicidal ideation, after adjusting for global depression. Given the lack of evidence-based pharmacotherapy guidelines for suicidal, depressed patients — an important public health population - this preliminary finding merits further study.

Neuropsychopharmacology (2012) 37, 697-706; doi:10.1038/npp.201।.247; published online 12 October 201 I
\end{abstract}

Keywords: suicide; depression; antidepressant; pilot; clinical trial

\section{INTRODUCTION}

Suicide results in $\sim 30000$ US deaths and costs an estimated $\$ 33$ billion annually in addition to immeasurable suffering (Corso et al, 2007). Suicide is most often associated with a depressive disorder (Mann et al, 2005), but antidepressant clinical trials have generally excluded suicidal patients. Randomized antidepressant trials designed a priori to study depressed suicide attempters or ideators are rare, resulting in scant evidence to guide treatment for these elevated risk patients. Most antidepressant trials have not measured suicidal ideation and behavior systematically, leading, in some cases, to contradictory findings from analyses of spontaneously reported adverse events versus rating scale

*Correspondence: Dr MF Grunebaum, Molecular Imaging and Neuropathology Division, New York State Psychiatric Institute, I05 I Riverside Drive, Box 42, New York, NY 10032, USA, Tel: + I 212543 5842, Fax: + | 212543 6017, E-mail: mfg |4@columbia.edu Received II April 20 I I; revised 29 July 201 I; accepted I September 2011 data (Hammad et al, 2006; Carpenter et al, 2011). Elevated risk samples may enhance detection in clinical trials of differential treatment effects on suicidal behavior or ideation, which could advance public health.

The antidepressant section of the American Psychiatric Association Practice Guideline on suicidal patients states, 'non-tricyclic, non-MAOI antidepressants are relatively safe... on overdose,' but offers no other advice (Jacobs et al, 2003). No published antidepressant randomized clinical trial, to our knowledge, has a priori sought to enroll patients at elevated suicidal risk. Suicide attempt history and ideation severity are risk factors for suicide (Meyer et al, 2010). Prospective studies show that suicidal ideation increases the risk of attempts and suicide in mood disorders (Oquendo et al, 2004a; Fawcett et al, 1990). Within 1 year of ideation onset, $90 \%$ of unplanned and $60 \%$ of planned first suicide attempts occur (Kessler et al, 1999).

There is clinical equipoise regarding the effects of predominantly serotonergic versus noradrenergic antidepressants on suicidal ideation. Of 10 studies, 5 suggested an advantage for serotonergic drugs (Gonella et al, 1990; 
Kasper et al, 1995; Sacchetti et al, 1991; Montgomery et al, 1978; Mahapatra and Hackett, 1997), 4 found similar efficacy (Lapierre, 1991; Judd et al, 1993; Möller and Steinmeyer, 1994; Tollefson et al, 1994), and 1 (Marchesi et al, 1998) suggested a noradrenergic advantage. Most of these relied on one scale item to measure suicidal ideation. None used a dedicated scale administered by independent, blinded raters and none specifically recruited patients with suicidality. Neurobiological depression research targets many putative mechanisms, but clinicians still tend to group antidepressants by predominant monoaminergic effects. Suicidal behavior is associated with serotonin system hypofunction (Mann, 2003); thus, we hypothesized that a serotonin reuptake inhibitor (SSRI) would be more beneficial for suicidal behavior and ideation than a predominantly nonserotonergic antidepressant.

SSRIs and bupropion comprise the five most prescribed US antidepressants (Drug Topics staff, 2010a, 2010b). SSRIs primarily enhance serotonin neurotransmission whereas bupropion is a norepinephrine-dopamine reuptake inhibitor (NDRI) with minimal (or no) direct effects on serotonin (Baldessarini, 2006). Similar antidepressant efficacy of these drugs (Thase et al, 2005; Gartlehner et al, 2008; Cipriani et al, 2009), and their relative safety on overdose, facilitates comparison of effects on suicidal ideation or behavior.

The primary aim of this study was to collect pilot data to explore if an SSRI antidepressant medication would be different from the NDRI, bupropion, for reducing suicidal behavior, ideation, and neuropsychological measures of impulsivity. A secondary outcome was global depression, measured using the 17-item Hamilton Depression Rating Scale after subtracting out the suicide item (mHDRS-17) (Hamilton, 1960). We enrolled depressed patients at elevated suicidal risk, specifically a history of a suicide attempt or current suicidal ideation. We hypothesized that suicidal behavior and ideation would improve more with the SSRI, paroxetine, compared with bupropion. We report here on suicidal behavior, ideation, and mHDRS-17 depressive symptoms. A follow-up paper will report neuropsychological outcomes.

\section{PATIENTS AND METHODS}

\section{Patients}

Patients 18 to 75 years old with a current episode of DSM IV major depressive disorder, scoring $\geqslant 16$ on the HDRS-17 (all items) (Hamilton, 1960), and who reported either a past suicide attempt or current suicidal ideation or both were eligible. Past attempters without current ideation were eligible. The first eight subjects were enrolled under inclusion criteria requiring a suicide attempt, after which eligibility was changed to include current ideation without past attempt because of challenges in recruitment. The ideation threshold for nonattempters was a score of $\geqslant 2$ on HDRS item 3 (suicide), 'wishes to be dead or has any thoughts of possible death to self (Hamilton, 1960). Patients with suicide plan or intent were enrolled if they consented to voluntary admission to our research unit. Other risk mitigation strategies included a research psychiatrist on-call at all times, available between time points for consultations and emergencies, and careful ongoing assessment of mood, side effects, and review of procedures to follow if patients became acutely suicidal.

Exclusions were: bipolar disorder, psychosis, anorexia or bulimia nervosa, current SSRI or bupropion use for other indications (eg, anxiety), drug or alcohol dependence within 6 months, unstable medical illness, contraindication to either drug, nonresponse to three other SSRIs, paroxetine, or bupropion in the past 2 years (at least $2 / 3$ maximum approved dose for $\geqslant 6$ weeks), pregnancy or lactation, and lack of capacity to consent.

This single site trial was conducted at Columbia University Medical Center/New York State Psychiatric Institute. Participants were recruited via local media and internet advertising, and clinician referral. After complete description of the study to subjects, written informed consent was obtained.

\section{Intervention}

Patients were randomized to extended-release oral paroxetine or bupropion. Pills were identically over-encapsulated and each vial label had both medication names, so that patients did not know which one they were taking, but only whether to take 1,2 , or 3 pills daily.

Participants met with a study psychiatrist for pharmacotherapy and with a psychologist for ratings. Assessments were weekly for 8 weeks, and then monthly for an additional 16 weeks. Daily dose was paroxetine $25 \mathrm{mg}$ or bupropion $150 \mathrm{mg}$ in weeks 1 and 2 and paroxetine $37.5 \mathrm{mg}$ or bupropion $300 \mathrm{mg}$ in weeks 3 and 4 . After 4 weeks, the protocol permitted an increase to paroxetine $50 \mathrm{mg}$ or bupropion $450 \mathrm{mg}$ daily, if indicated. Concomitant benzodiazepine (up to lorazepam $6 \mathrm{mg}$ daily or its equivalent) for anxiety or zolpidem for insomnia were allowed. The 16week continuation phase remained blinded if the patient had a satisfactory response to the randomized drug. Patients with an inadequate response or intolerable side effects were switched to open treatment.

\section{Outcome and Measures}

Research assessors were $\mathrm{PhD}$ or masters level psychologists. Axis I and II diagnoses were made using the Structured Clinical Interview for DSM-IV (SCID I and II) (Spitzer et al, 1990; First et al, 1996). Diagnostic and suicide attempt classifications were made in a weekly consensus conference including psychologists and psychiatrists. Suicidal events were assessed with the Columbia Suicide History Form (Oquendo et al, 2003), and were classified as major (an attempt) or minor (increase in ideation requiring clinical intervention, such as hospitalization) (Oquendo et al, 2004b).

The clinician-rated Scale for Suicidal Ideation (SSI) (Beck et al, 1979) was used weekly for 8 weeks, and then monthly. It has 19 items scaled 0 (least severe) to 2 (most severe) and total score is the sum, ranging from 0 to 38 (Beck et al, 1979). Items measure frequency, intensity, and attitudes toward suicidal thoughts, feelings of control over them, and suicide plans (Beck et al, 1979). Mean score in 90 inpatients hospitalized for suicidal ideation was $9.4 \pm 8.4$ versus $4.4 \pm 5.8$ in outpatients (Beck et al, 1979). 
Global depressive symptoms, not hypothesized to differ by drug group, were assessed weekly for 8 weeks and then monthly with the HDRS-17 (Hamilton, 1960). Raters were trained by in-person observation and participated in weekly reliability monitoring using video and audio tapes. The intraclass correlation for the HDRS-17 was $94 \%$ and for the SSI was $97 \%$.

Study psychiatrists measured treatment nonadherence since the last visit by asking patients to estimate proportion of missed doses. Side effects were assessed with the Treatment Emergent Symptom Scale (Vinar, 1971).

\section{Sample Size}

The study was powered for $N=50$ subjects per group based on naturalistic treatment data from our clinic showing more aggression, a correlate of suicidal behavior (Mann et al, 1999), using the Brown Goodwin Aggression Inventory (Brown et al, 1979), during 3-month follow-up of depressed subjects on bupropion $(N=5)$ vs SSRI $(N=27)$. An interim data analysis with $N=68$ subjects was performed to generate data for a grant application without identifying the treatment groups. This showed a main effect of treatment and an interaction of treatment with baseline suicidal ideation severity on follow-up ideation. After consulting with clinical colleagues, statisticians, and the IRB, a decision was made to stop enrollment. Here we report an analysis of the complete data set, which included $N=74$ subjects, as enrollment continued during the period of the interim analysis. The data set was considered complete when all subjects who enrolled at the time the recruitment was suspended had finished participation.

\section{Randomization and Blinding}

Patients, psychiatrists, and assessors were blind to treatment. The randomization sequence was generated by a pharmacist separate from the research team and was stratified on: (1) inpatient versus outpatient and (2) lifetime history of suicide attempt (yes/no). Random numbers were generated using Excel 5.0 Data Analysis ToolPak (Microsoft). Within each stratum, subjects were randomized in blocks of four (AABB, ABAB, BABA, and BBAA) so that allocation was $1: 1$ between groups. Unblinding occurred after all subjects had completed study treatment.

\section{Statistical Methods}

Our primary analysis investigated treatment effects on suicidal behavior and ideation. The analysis was modified intention to treat: (1) we excluded one patient from the paroxetine arm who was randomized and never returned for any assessment and (2) we excluded three other patients (two in the bupropion arm and one in the paroxetine arm) because of ineligibility discovered after randomization, which is justified under the intention-to-treat principle as ineligibility voided their enrollment (Figure 1). We used SPSS version 17 (SPSS) and SAS (SAS Institute, Cary, NC). Univariate tests compared groups on baseline characteristics, time in study, and concomitant medications. Kaplan-Meier survival analysis tested the association of treatment group with time to the first suicidal 'event' during the 24 weeks.
We modeled follow-up suicidal ideation using generalized least squares regression, a variant of mixed models, for correlated longitudinal data (Pinheiro and Bates, 2000). We modeled the acute and continuation phases separately. We anticipated smaller changes in suicidal ideation at later time points, and hence used a log transformation of time as a covariate. We compared and selected covariance structure using the Bayesian Information Criterion (BIC), which balances model fit and complexity (Rao and $\mathrm{Wu}, 2001$ ). We examined residuals $v s$ predicted values for influential data points.

Baseline suicidal ideation score ( $\left.\mathrm{SSI}_{\text {baseline }}\right)$ was a covariate in all models of follow-up ideation, a method used widely in longitudinal models for randomized trials (Fitzmaurice et al, 2004). We also adjusted for baseline mHDRS-17. Continuation phase suicidal ideation scores tended to be low ( $63 \%$ were 0$)$, and hence we used a natural $\log$ transformation of the score after adding 1 .

Exploratory model selection used backward elimination of interaction terms based on the BIC. Assuming other variables to be equal, we computed mean predicted differences in follow-up suicidal ideation by treatment. Standard errors used to compute $p$-values were confirmed with the bootstrap method (Efron and Tibshirani, 1993). Comparison of concomitant medication use between treatment groups was preplanned, but without a specific hypothesis.

\section{RESULTS}

\section{Study Patients}

The first patient enrolled in February 2005 and the last in July 2009 with follow-up completed in January 2010. Figure 1 summarizes patient flow. The analysis included 38 subjects randomized to bupropion and 36 to paroxetine. Treatment groups did not differ in baseline sociodemographic, clinical, or suicidal characteristics (Table 1).

\section{Follow-Up and Exposure to Intervention}

Week 1-8 attrition was $32 \%$ overall and did not differ by treatment. A total of $9 / 36$ paroxetine and 15/38 bupropion subjects did not complete 8 weeks of randomized treatment $\left(\chi^{2}=1.77, \mathrm{df}=1, p=0.18\right)$. In addition, $29 / 38(76 \%)$ on bupropion and $24 / 36(67 \%)$ on paroxetine did not complete 24 weeks of randomized treatment. Some patients who had to be withdrawn into open treatment because of side effects or nonresponse switched to the drug from the other treatment arm, and consequently we emphasize results from the acute phase. Figure 1 lists reasons for attrition.

Time to last assessment during the 24 weeks did not differ between groups $\left(\right.$ Mean $_{\text {paroxetine }}=17.9 \pm 8.1$, Mean $_{\text {bupropion }}=16.8 \pm 8.8$ weeks; Wilcoxon $Z=-0.59$, $p=0.55)$. The median dose of paroxetine was $37.5 \mathrm{mg}$ $($ mean $=33.7 \pm 14.3$ ) and for bupropion was $300 \mathrm{mg}$ $($ mean $=275.3 \pm 135.8)$.

\section{Suicidal Events}

There were a total of 10 suicidal events during the 24-week follow-up: 1/10 was an acetaminophen overdose requiring 


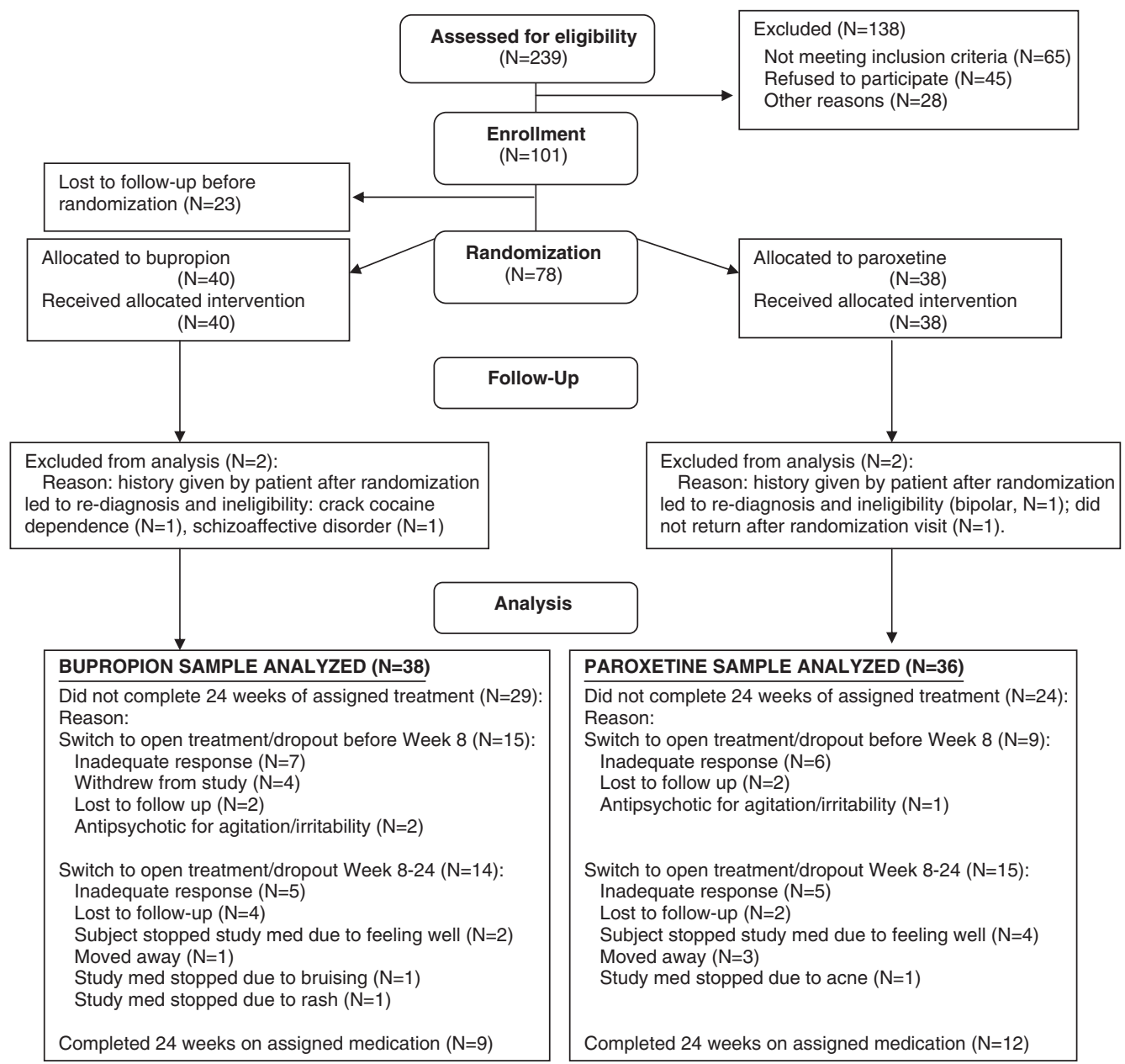

Figure I Flow diagram of progress through phases of the parallel randomized trial of two groups (enrollment, intervention allocation, follow-up, and data analysis) (Schulz et al, 20I0).

medical admission for treatment of a hepatotoxic blood level followed by transfer to a psychiatric unit; 3/10 involved increased ideation or behavior by inpatients prompting initiation of close observation or withdrawal from the protocol with prescription of quetiapine for agitation; 6/10 were increased ideation of which 4 led to inpatient admission. In the paroxetine arm, four subjects accounted for one event each. In the bupropion arm, one subject had three events (but was counted only once in the survival analysis of time to the first event) and three subjects had one event each. Treatment was not associated with time to the first suicidal event during the week 1-8 acute phase (log rank $\left.\chi^{2}=1.03, \mathrm{df}=1, p=0.31\right)$ or the complete 24 -week follow-up (log rank $\chi^{2}=0.17, \mathrm{df}=1, p=0.68$ ).

\section{Suicidal Ideation: Acute Phase (Weeks 1-8)}

Baseline suicidal ideation severity $($ mean $=9.0, \mathrm{SD}=7.1)$ did not differ by treatment (Table 1). Suicidal ideation during acute treatment had high variability, making interpretation difficult (Figures 2 and 3). The means (SD) for suicidal ideation and for mHDRS-17 at each time point are provided in Table 2.

To assess traditional RCT outcomes, we tested a model of follow-up SSI with main effects of treatment, randomization strata, time, $\mathrm{SSI}_{\text {baseline, }} \mathrm{mHDRS}-17_{\text {baseline, }}$ and a treatment $\times$ time interaction. The treatment main effect $(p=0.07)$ and treatment $\times$ time interaction $(p=0.27)$ were not significant.

More generally, we performed exploratory model selection to determine the best fitting model of acute suicidal ideation. We tested a model with main effects as above and interactions of treatment $\times$ time, treatment $\times \mathrm{SSI}_{\text {baseline, }}$ time $\times \mathrm{SSI}_{\text {baseline, }}$ and a three-way interaction of treatment $\times$ time $\times$ SSI $_{\text {baseline }}$. We used the BIC to select the best model from the group that included the full model, models without the three-way interaction but with all combinations of two-way interactions, and the model with no interaction (data available on request). The model with the best (smallest) BIC included interactions of treatment $\times$ time and treatment $\times \mathrm{SSI}_{\text {baseline }}$ (Table 3 ). This model had a lower BIC, indicating a better fit, than the traditional model without the treatment $\times \mathrm{SSI}_{\text {baseline }}$ interaction.

The treatment $\times \mathrm{SSI}_{\text {baseline }}$ interaction effect on follow-up ideation was significant (Table 3). For each point that $\mathrm{SSI}_{\text {baseline }}$ was more severe, follow-up ideation was 0.29 points lower, favoring paroxetine at every time point. Figures 2 and 3 illustrate change in suicidal ideation over time in subgroups divided by treatment and median split of SSI $_{\text {baseline. }}$

In order to ascertain the robustness for the finding regarding the treatment $\times \mathrm{SSI}_{\text {baseline }}$ interaction effect, we 
Table I Demographic and Baseline Characteristics of Study Participants by Treatment $(N=74)$

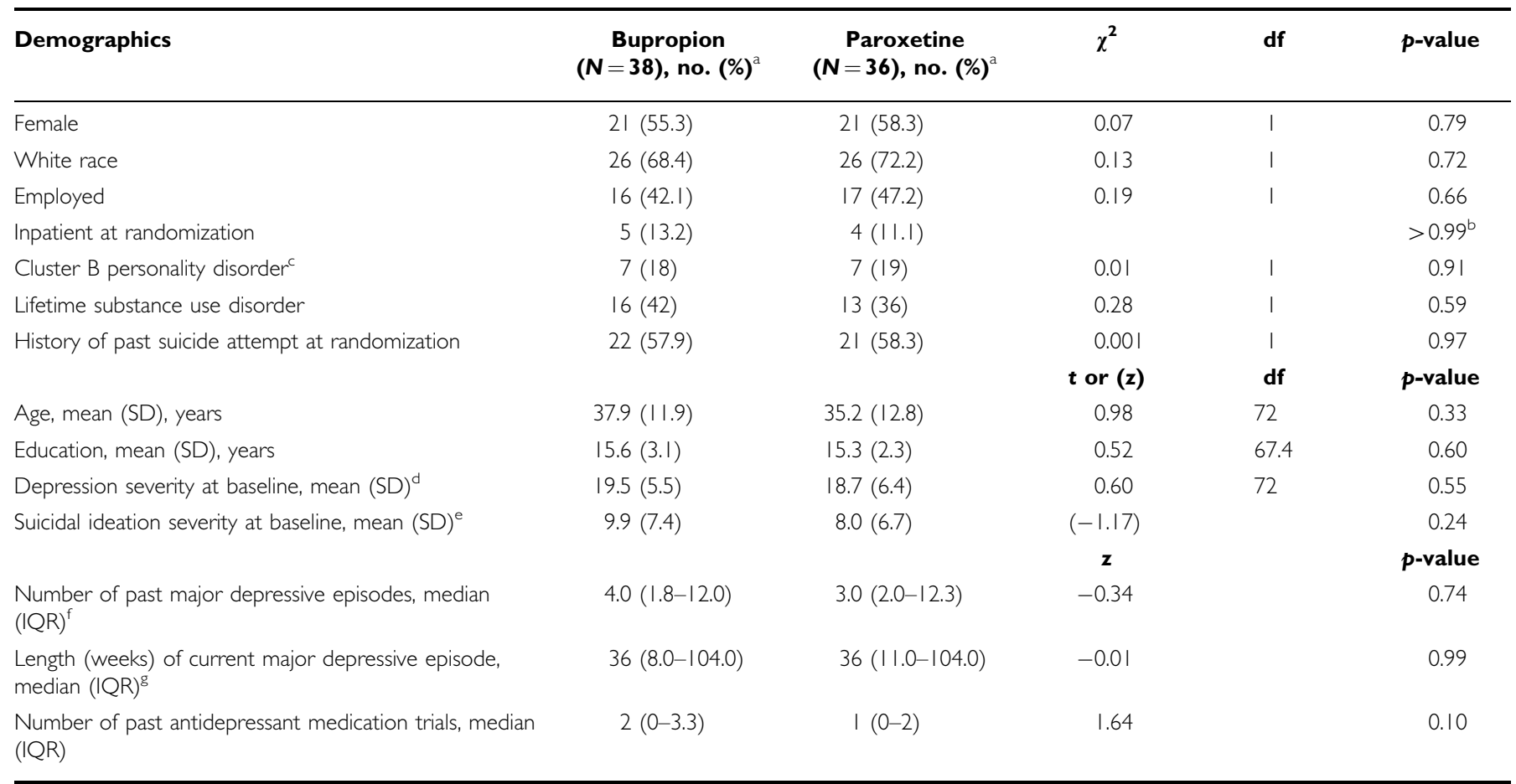

${ }^{\mathrm{a}}$ Except where otherwise noted.

'Fisher's exact test.

${ }^{\mathrm{C} C}$ Cluster B personality disorder = borderline, antisocial, narcissistic, or histrionic.

d I7-item Hamilton Depression Rating Scale (Hamilton, 1960).

eScale for Suicidal Ideation score (Beck et al, 1979).

fTruncated at 50.

'Truncated at 104 weeks.

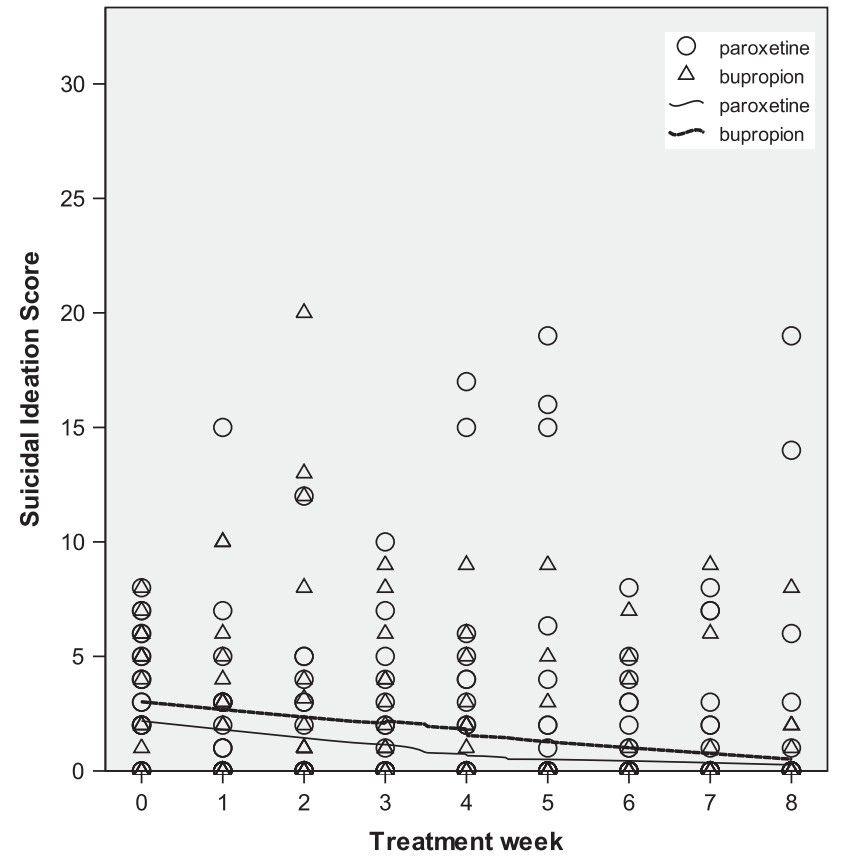

Figure 2 Scatter-plot of Scale for Suicidal Ideation (SSI) (Beck et al, 1979) score vs time, by treatment, in patients with baseline SSI $\leqslant 8$. Locally weighted polynomial regression lines for scatter-plot smoothing (Cleveland, 1979) use $80 \%$ of points to fit and Epanechnikov kernel. Data points may represent more than one patient.

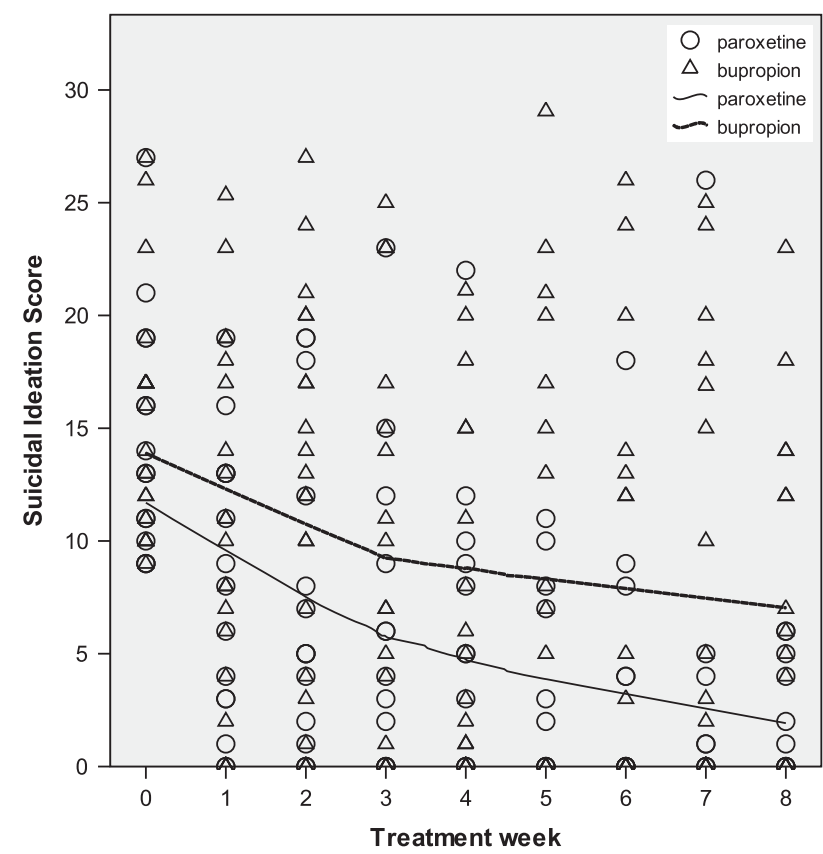

Figure 3 Scatter-plot of Scale for Suicidal Ideation (SSI) (Beck et al, 1979) score vs time, by treatment, in patients with baseline SSI $\geqslant 9$. Locally weighted polynomial regression lines for scatter-plot smoothing (Cleveland, 1979) use $80 \%$ of points to fit and Epanechnikov kernel. Data points may represent more than one patient. 
Table 2 Mean (SD) of Scale for Suicidal Ideation (SSI) ${ }^{\mathrm{a}}$ Score; and mHDRS- $17^{\mathrm{b}}$ at Each Time Point During Treatment with Paroxetine $(N=36)$ vs Bupropion $(N=38)$

Baseline Week I Week 2 Week 3 Week 4 Week 5 Week 6 Week 7 Week 8 Month 3 Month 4 Month 5 Month 6

\begin{tabular}{|c|c|c|c|c|c|c|c|c|c|c|c|c|c|}
\hline \multicolumn{14}{|c|}{ Scale for Suicidal Ideation score } \\
\hline Bupropion & $9.9(7.4)$ & $7.3(7.2)$ & $8.4(8.3)$ & $7.1(7.6)$ & $5.2(6.5)$ & $6.7(8.9)$ & $5.8(8.1)$ & $6.5(8.6)$ & $4.7(6.6)$ & $2.2(3.8)$ & $1.1(2.4)$ & $3.5(4.7)$ & $4.2(8.0)$ \\
\hline Paroxetine & $8.0(6.7)$ & $4.6(5.5)$ & 4.I (5.7) & $3.6(5.3)$ & $4.3(5.8)$ & $3.5(5.5)$ & $2.3(4.0)$ & $2.5(5.3)$ & $2.3(4.5)$ & $2.8(4.6)$ & $0.7(1.6)$ & $1.3(3.1)$ & $3.4(6.1)$ \\
\hline Bupropion & $17.6(5.2)$ & 15.3 (5.5) & $14.5(6.1)$ & I3.8 (5.5) & $12.7(6.3)$ & $12.8(5.9)$ & | 1.3 (6.8) & $12.3(6.6)$ & 10.1 (6.5) & $10.2(7.8)$ & $7.6(4.6)$ & $9.5(6.5)$ & $9.5(6.1)$ \\
\hline Paroxetine & $16.9(5.8)$ & | $4.3(4.8)$ & | $3.2(5.5)$ & I I.5 (5.5) & $12.5(6.5)$ & $9.8(5.9)$ & $11.3(7.1)$ & $10.8(6.8)$ & $9.8(5.8)$ & $7.7(5.5)$ & $7.8(6.7)$ & $6.4(5.1)$ & $9.3(7.1)$ \\
\hline
\end{tabular}

${ }^{a}$ Scale for Suicidal Ideation (Beck et al, 1979).

b I7-item Hamilton Depression Rating Scale score after subtracting suicide item (Hamilton, 1960).

Table 3 Selected Exploratory Model of Suicidal Ideation During Acute Treatment (Weeks I-8) with Paroxetine (N=36) vs Bupropion $(N=38)^{\mathrm{a}}$

\begin{tabular}{|c|c|c|c|c|}
\hline Variable & Estimate $(95 \% \mathrm{Cl})$ & $t$ & df & $p$-value \\
\hline Treatment & $0.25(-3.23$ to 3.74$)$ & 0.14 & 99.51 & 0.89 \\
\hline Inpatient status at randomization & $0.26(-2.80$ to 3.32$)$ & 0.17 & 61.02 & 0.87 \\
\hline Past suicide attempt at randomization ${ }^{\text {b }}$ & $0.44(-1.49$ to 2.37$)$ & 0.46 & 60.64 & 0.65 \\
\hline Baseline $m H D R S-17^{c}$ & $0.15(-0.04$ to 0.33$)$ & 1.56 & 62.63 & 0.13 \\
\hline Time & $-1.49(-2.52$ to -0.48$)$ & -2.89 & 153.97 & 0.004 \\
\hline Baseline suicidal ideation $^{d}$ & 0.58 (0.39 to 0.78$)$ & 5.97 & 63.97 & $<0.001$ \\
\hline Treatment $\times$ time & $0.82(-0.60$ to 2.25$)$ & 1.14 & 149.93 & 0.26 \\
\hline Treatment $\times$ baseline suicidal ideation & $-0.29(-0.57$ to -0.023$)$ & -2.17 & 59.99 & 0.03 \\
\hline
\end{tabular}

${ }^{a}$ Generalized least squares regression model selected using Bayesian Information Criterion (BIC); first-order autoregressive moving average covariance;

outcome = Scale for Suicidal Ideation (Beck et al, 1979) score during treatment.

bSubject had history of a past suicide attempt (lifetime) at baseline (yes/no).

'The 17-item Hamilton Depression Rating Scale score after subtracting suicide item (Hamilton, 1960).

'Baseline score on Scale for Suicidal Ideation (Beck et al, 1979).

conducted various sensitivity analyses. A test of the model including an indicator variable for the eight subjects enrolled under the initial attempter-only criteria gave the same results (estimate $=-0.29, p=0.035$ ). A test of the model after removing one possibly influential data point gave similar results (estimate $=-0.32, p=0.02$ ). Restricting the model to weeks $4-8$, when doses of both drugs were optimal, strengthened the interaction effect favoring paroxetine (estimate $=-0.45, p=0.003$ ).

\section{Suicidal Ideation Model Predictions}

For subjects at the 75th percentile of SSI baseline (score $=13.3$ ), the fitted model predicts that follow-up ideation would be 3.7 points lower after 1 week $(p=0.009)$ and 2.5 points lower after 4 weeks of treatment $(p=0.03)$ on paroxetine relative to bupropion (Table 4). Predicted treatment differences at weeks 8,16 , and 24 were not significant according to the model $(p=0.65,0.14$, and 0.08 , respectively).

\section{Worsening of Ideation}

To assess possible deleterious treatment effects on suicidal ideation, we tested a mixed logistic regression model of worsening (increase of $\geqslant 5$ points over $\mathrm{SSI}_{\text {baseline }}$ ) during the acute phase. Among patients at the 75 th percentile of $\mathrm{SSI}_{\text {baseline, }}$ there was a trend for bupropion treatment having 5.9 times higher odds of worsening SSI after 1 week compared with paroxetine (estimate $=1.77, t=1.89$, $\mathrm{df}=121.4, \quad p=0.06, \quad \mathrm{OR}=5.9, \quad 95 \% \quad \mathrm{CI}=0.94-36.70) . \quad \mathrm{A}$ treatment $\times$ time interaction showed that this effect diminished over time (estimate $=1.06, t=2.02, \mathrm{df}=84.11$, $p=0.05)$.

\section{Acute Depressive Symptoms without Suicide Item}

To investigate the effects of acute treatment on depressive symptoms other than suicidality, we modeled mHDRS-17 at each time point. Predictors were treatment, randomization strata, time, $\mathrm{SSI}_{\text {baseline, }} \mathrm{mHDRS}-17_{\text {baseline, }}$ and interaction terms for treatment $\times$ time and treatment $\times$ mHDRS$17_{\text {baseline. The latter interaction was significant favoring }}$ paroxetine (estimate $=-0.46,95 \% \mathrm{CI}=0.83$ to 0.08 , $t=2.41, \mathrm{df}=67.56, p=0.02)$. For each point more severe mHDRS-17 baseline, these symptoms were 0.46 point lower with paroxetine compared with bupropion at every acute follow-up time point. Treatment $\times$ time was not significant $(p=0.74)$. 
Table 4 Mean Predicted Difference in Scale for Suicidal Ideation (SSI) (Beck et al, 1979) Score During Acute Treatment with Paroxetine $(N=36)$ vs Bupropion $(N=38)$

\begin{tabular}{lcll}
\hline $\begin{array}{l}\text { Number of } \\
\text { treatment }\end{array}$ & $\begin{array}{c}\text { Mean predicted difference in } \\
\text { SSI score }(95 \% \mathrm{Cl}) \text { between } \\
\text { weeks completed } \\
\text { freatment groups at } \\
\text { follow-up time point }\end{array}$ & p-value \\
\hline
\end{tabular}

\begin{tabular}{|c|c|c|c|}
\hline \multicolumn{4}{|c|}{ Subjects at 75th percentile of baseline SSI score $=13.3$} \\
\hline Week I & $-3.7(-6.4$ to -0.9$)$ & -2.62 & 0.009 \\
\hline Week 4 & $-2.5(-4.7$ to -0.3$)$ & -2.23 & 0.03 \\
\hline Week 8 & $-1.9(-4.5$ to -0.6$)$ & -1.49 & 0.14 \\
\hline \multicolumn{4}{|c|}{ Subjects at median of baseline SSI score $=7.5$} \\
\hline Week I & $-1.9(-4.5$ to 0.6$)$ & -1.53 & 0.13 \\
\hline Week 4 & $-0.8(-2.8$ to 1.1$)$ & -0.82 & 0.41 \\
\hline Week 8 & $-0.2(-2.6$ to 2.1$)$ & -0.21 & 0.84 \\
\hline \multicolumn{4}{|c|}{ Subjects at 25th percentile of baseline SSI score $=2.8$} \\
\hline Week I & $-0.6(-3.5$ to 2.4$)$ & -0.37 & 0.71 \\
\hline Week 4 & $0.6(-1.9$ to 3.1$)$ & 0.45 & 0.65 \\
\hline Week 8 & $1.2(-1.7$ to 4.0$)$ & 0.79 & 0.43 \\
\hline
\end{tabular}

${ }^{a}$ (Scale for Suicidal Ideation) paroxetine - (Scale for Suicidal Ideation) bupropion. Positive number favors bupropion; negative number favors paroxetine.

\section{Treatment Adherence and Side Effects}

Subjects reported taking 'all/nearly all doses' since their last visit for $75 \%$ of bupropion ratings $(N=379)$ and $79 \%$ of paroxetine ratings $(N=399)$. Using a generalized least squares model, adjusted for randomization strata, drug group was not associated with adherence during the 8-week acute phase $(t=-0.42, \mathrm{df}=47.1, p=0.68)$ or the entire 24 weeks $(t=0.48, \mathrm{df}=164.2, p=0.43)$. Using a similar model, drug group was not associated with overall side effect intensity $(t=0.77, \mathrm{df}=62.5, p=0.44)$.

\section{Concomitant Medication}

Of the patients, $7 / 38(18 \%)$ on bupropion received zolpidem for insomnia vs $8 / 36(22 \%)$ on paroxetine $\left(\chi^{2}=0.17\right.$, $\mathrm{df}=1, p=0.68)$. In addition, $15 / 38(40 \%)$ on bupropion received a benzodiazepine versus $14 / 36(39 \%)$ on paroxetine $\left(\chi^{2}=0.003, \mathrm{df}=1, p=0.96\right)$. Maximum dose of benzodiazepine (mg lorazepam) in the bupropion group was double that in the paroxetine group $\left(\mathrm{Mean}_{\text {bupropion }}=3.6 \pm 2.8\right.$; Mean $_{\text {paroxetine }}=1.8 \pm 1.4 ; \quad$ Mann-Whitney $\quad U=153.0$, $p=0.03)$.

\section{DISCUSSION}

This pilot randomized clinical trial comparing paroxetine with bupropion treatment in depressed suicide attempters and ideators tested our hypotheses that suicidal behavior and ideation would improve more with paroxetine. Basic treatment main effects and treatment by time interactions were not found in support of these hypotheses.

Exploratory model selection analysis of acute treatment suggests that compared with bupropion: (1) patients with more severe global depressive symptoms apart from suicidality improved more in terms of depression on paroxetine, while controlling for $\mathrm{SSI}_{\text {baseline; }}$ and (2) patients

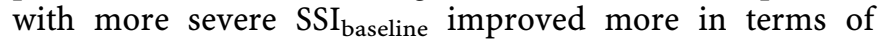
suicidal ideation on paroxetine, controlling for baseline depression. The model predicted that suicidal ideation was lower with paroxetine than bupropion treatment in patients with the highest $\mathrm{SSI}_{\text {baseline }}(75$ th percentile, score $=13.3$ ) by 3.7 points at week 1 and 2.5 points at week 4 . For comparison, the difference on the SSI between 'weak' $v s$ 'moderate to strong' desire to attempt suicide (item 4) is 1 point and between no plans and 'definite plans' for suicide (item 18) is 2 points (Beck et al, 1979). The nearly two-point difference between treatment groups in $\mathrm{SSI}_{\text {baseline }}$ does not explain these results as all models adjusted for SSI $_{\text {baseline }}$.

In patients presenting with the most severe suicidal ideation, the odds of worsening by $\geqslant 5$ points after 1 week were 5.9 times greater on bupropion compared with paroxetine $(p=0.06)$. This trend-level finding raises the question of whether bupropion-related activation may have contributed to early worsening of suicidal ideation in some patients. This hypothesis would be consistent with our finding that the bupropion group received twice the dose of benzodiazepine compared with the paroxetine group. Reported associations of anxiety (Fawcett et al, 1990), but not (Placidi et al, 2000), insomnia (Wojnar et al, 2009), and sedative-hypnotics (Brower et al, 2011) to suicidal ideation and behavior suggest complex relationships between these variables.

Our findings for suicidal ideation are consistent with studies reporting that more suicidal depression is associated with a better response to predominantly serotonergic antidepressants (Gonella et al, 1990; Kasper et al, 1995; Sacchetti et al, 1991; Montgomery et al, 1978; Mahapatra and Hackett, 1997). However, the neurobiological significance of our results is limited by serotonergic-noradrenergic interactions and neurotransmitter nonspecificity of both drugs (Baldessarini, 2006; Owens et al, 2008). Paroxetine is predominantly serotonergic, but in a novel assay of human serum samples, it showed potential norepinephrine transporter inhibition (hypothetically $10-20 \%$ at the doses used in our study) (Owens et al, 2008).

Our results for suicidal ideation are also consistent with the greater percentage of depressed paroxetine-treated patients with 'declining suicidal ideation' as compared with placebo in a recent meta-analysis (Carpenter et al, 2011). Seemingly contradictory to this latter result based on rating scale data, the meta-analysis of adverse events found more frequent suicidal behavior in depressed patients treated with paroxetine as compared with placebo, which appeared because of more events in young adults (Carpenter et al, 2011). Our study differs from this meta-analysis in several ways: (1) we compared paroxetine with bupropion, not placebo; (2) our study is a prospective, randomized clinical trial whereas meta-analysis is retrospective; (3) we selected for depressed attempters and ideators, whereas the meta-analysis mainly comprised trials that excluded suicidal patients; (4) our study randomization was stratified by the preexisting suicide risk factors of past attempt and current inpatient status; and (5) we did not analyze adverse events, which can be reported unsystematically (Carpenter et al, 2011).

We find different effects of treatment in patients who were more depressed or more suicidal at presentation. 
These are consistent with previous reports that greater baseline severity increases the ability to detect treatment differences in clinical trials (Khan et al, 2002; Kirsch et al, 2008; Fournier et al, 2010).

The relatively low base rate of suicidal behavior is a challenge for clinical trials and forces a focus on proxy outcomes with higher base rates such as suicidal ideation. Clinicians assess suicidal ideation in part to evaluate need for hospitalization because of its predictive validity for risk of suicide attempts (Oquendo et al, 2004a) and suicide (Fawcett et al, 1990; Beck et al, 1999). Depression appears to predict suicide attempts via its effect on suicidal ideation (Nock et al, 2010). Most published antidepressant randomized clinical trials excluded suicidal patients and did not assess ideation and behavior systematically. Our pilot study, in a sample with clinically significant suicidal ideation and nearly $60 \%$ with past attempt, shows that such a randomized clinical trial is feasible and can yield useful results.

There has been a concern that some antidepressants may, on average, lead to improvement, but also possibly worsen ideation or trigger an attempt in vulnerable patients. We found 5.9 times greater odds of worsening suicidal ideation with bupropion compared with paroxetine and a statistical trend level of significance, which if confirmed would be important clinically. That result is also consistent with the reported lower rate of rating scale-based treatment-emergent suicidal behavior or ideation found in paroxetinetreated patients compared with placebo across all indications (Carpenter et al, 2011).

The main study limitations are the small sample and exploratory nature of the analyses. However, the week 1 model prediction of 3.7 points lower suicidal ideation with paroxetine relative to bupropion treatment $(p=0.009)$ would survive correction for several statistical tests. Bupropion had a slower titration schedule, but restricting the analysis to weeks 4-8 strengthened the treatment $\times \mathrm{SSI}_{\text {baseline }}$ interaction effect, suggesting that it was not simply because of an early dose advantage for paroxetine. We increased the initial dose after 2 weeks to give patients a longer accommodation period, because of concern about a hypothesized 'activation syndrome.' The trend toward more worsening suicidal ideation, in those with the severest $\mathrm{SSI}_{\text {baseline, }}$ after 1 week on bupropion raises questions about possible noradrenergic effects on a putative 'activation syndrome.' The latter is consistent with a reported higher rate of suicide attempts despite less depressive relapse in remitted depressed patients maintained for one year on maprotiline, a norepinephrine reuptake inhibitor, compared with placebo $(N=1141$; $p=0.03$ ) (Rouillon et al, 1989). Our analyses of follow-up suicidal ideation adjusted for baseline mHDRS-17, suggesting that these results are at least partly independent of baseline depression severity.

The $32 \%$ acute-phase attrition rate is in line with the average 33\% rate found in four other 8-week bupropion $v$ s SSRI randomized trials in MDD $(N=1011)$ (Thase et al, 2005). The lack of differential drug effects that we observed during the continuation phase may be explained by the high cumulative 6-month attrition, and low variance in ideation because of robust acute improvement. Clearly, all of these findings must be replicated in an adequately powered randomized clinical trial, but if confirmed would have importance for practice.
We did not exclude substance use disorder, because it is a risk factor for suicidal behavior, and that made the findings more generalizable. It also did not explain the treatment findings because the rate of lifetime substance use disorder was the same in both study arms. We did not measure plasma drug levels; however, adherence self-report correlates with antidepressant prescription refills (Saunders et al, 1998) and did not differ by treatment.

Data on prior treatment resistance, which can affect outcome, were limited. The drug arms did not differ in number of past major depressive episodes, length of current episode, or number of prior antidepressant medication trials. This makes it unlikely that an imbalance in treatment resistance explains the findings.

Our exploratory results suggest that an adequately powered trial is warranted to determine whether SSRIs have clinically meaningful advantages $v s$ nonserotonergic antidepressants on suicidal behavior and ideation in depressed patients presenting with more severe suicidal ideation.

\section{ACKNOWLEDGEMENTS}

This study was initiated with a NARSAD Young Investigator grant (Grunebaum) and completed under National Institute of Mental Health K23 MH076049 (Grunebaum). Other support included National Institute of Mental Health Grants MH48514 and MH62185. We thank all the hard-working research team members and the brave patients who participated in this study.

\section{DISCLOSURE}

To defray costs, Paxil CR and Wellbutrin XL pills were donated by GlaxoSmithKline in the first 3 years of this study and were purchased with grant funds thereafter. Dr Mann received research grant support for unrelated brain imaging studies from GlaxoSmithKline and Novartis. Dr Duan received research support from Pfizer for unrelated health services research. The other authors declare no conflict of interest.

\section{Disclaimer}

The sponsors (NARSAD and NIMH) had no role in the design and conduct of the study; the collection, analysis, and interpretation of the data; or the preparation, review, or approval of the manuscript. They had no access to the data or any editorial role in this manuscript.

\section{REFERENCES}

Baldessarini RJ (2006). Drug therapy of depression and anxiety disorders. In: Brunton LL, Lazo JS, Parker KL (eds). Goodman and Gilman's The Pharmacological Basis of Therapeutics. McGraw-Hill: New York. pp 429-459.

Beck AT, Brown GK, Steer RA, Dahlsgaard KK, Grisham JR (1999). Suicide ideation at its worst point: a predictor of eventual suicide in psychiatric outpatients. Suicide Life Threat Behav 29: 1-9.

Beck AT, Kovacs M, Weissman A (1979). Assessment of suicidal intention: the scale for suicide ideation. J Consult Clin Psychol 47: 343-352. 
Brower KJ, McCammon RJ, Wojnar M, Ilgen MA, Wojnar J, Valenstein M (2011). Prescription sleeping pills, insomnia, and suicidality in the National Comorbidity Survey Replication. J Clin Psychiatry 72: 515-521.

Brown GL, Goodwin FK, Ballenger JC, Goyer PF, Major LF (1979). Aggression in human correlates with cerebrospinal fluid amine metabolites. Psychiatry Res 1: 131-139.

Carpenter DJ, Fong R, Kraus JE, Davies JT, Moore C, Thase ME (2011). Meta-analysis of efficacy and treatment-emergent suicidality in adults by psychiatric indication and age subgroup following initiation of paroxetine therapy: a complete set of randomized placebo-controlled trials. J Clin Psychiatry; e-pub ahead of print 22 February 2011; e1-e12.

Cipriani A, Furukawa TA, Salanti G, Geddes JR, Higgins JPT, Churchill $\mathrm{R}$ et al (2009). Comparative efficacy and acceptability of 12 new-generation antidepressants: a multiple-treatments meta-analysis. Lancet 373: 746-758.

Cleveland WS (1979). Robust locally weighted regression and smoothing scatterplots. J Amer Stat Assoc 74: 829-836.

Corso PS, Mercy JA, Simon TR, Finkelstein EA, Miller TR (2007). Medical costs and productivity losses due to interpersonal and selfdirected violence in the United States. Am J Prev Med 32: 474-482.

Drug Topics staff (2010a). 2009 Top 200 generic drugs by total prescriptions. Available at: http://drugtopics.modernmedicine.com/drugtopics/data/articlestandard/drugtopics/252010/674982/ article.pdf.

Drug Topics staff (2010b). 2009 Top 200 branded drugs by total prescriptions. Available at: http://drugtopics.modernmedicine. com/drugtopics/data/articlestandard//drugtopics/252010/674969/ article.pdf.

Efron B, Tibshirani RJ (1993). An Introduction to the Bootstrap. Chapman and Hall: Boca Raton, FL.

Fawcett J, Scheftner WA, Fogg L, Clark DC, Young MA, Hedeker D et al (1990). Time-related predictors of suicide in major affective disorder. Am J Psychiatry 147: 1189-1194.

First MB, Spitzer RL, Gibbon M, Williams JMG, Benjamin L (1996). Structured Clinical Interview for DSM-IV Axis II Personality Disorders (SCID-II), (Version 2.0). Biometrics Research Department, New York State Psychiatric Institute: New York. 49 pp.

Fitzmaurice GM, Laird NM, Ware JH (2004). Applied Longitudinal Analysis. Wiley: Hoboken, NJ.

Fournier JC, DeRubeis RJ, Hollon SD, Dimidjian S, Amsterdam JD, Shelton RC et al (2010). Antidepressant drug effects and depression severity: a patient-level meta-analysis. J Am Med Assoc 303: 47-53.

Gartlehner G, Gaynes BN, Hansen RA, Thieda P, DeVeaugh-Geiss A, Krebs EE et al (2008). Comparative benefits and harms of second-generation antidepressants: background paper for the American College of Physicians. Ann Intern Med 149: 734-750.

Gonella G, Baignoli G, Ecari U (1990). Fluvoxamine and imipramine in the treatment of depressive patients: a doubleblind controlled study. Curr Med Res Opin 12: 177-184.

Hamilton M (1960). A rating scale for depression. J Neurol Neurosurg Psychiatry 23: 56-62.

Hammad TA, Laughren T, Racoosin J (2006). Suicidality in pediatric patients treated with antidepressant drugs. Arch Gen Psychiatry 63: 332-339.

Jacobs DG, Baldessarini RJ, Conwell Y, Fawcett JA, Horton L, Meltzer $\mathrm{H}$ et al (2003). Practice Guideline for the Assessment and Treatment of Patients with Suicidal Behaviors. American Psychiatric Publishing: Arlington, VA.

Judd FK, Moore K, Norman TR, Burrows GD, Gupta RK, Parker G (1993). A multicentre double blind trial of fluoxetine versus amitriptyline in the treatment of depressive illness. Aust $N Z J$ Psychiatry 27: 49-55.

Kasper S, Möller H-J, Montgomery SA, Zondag E (1995). Antidepressant efficacy in relation to item analysis and severity of depression: a placebo-controlled trial of fluvoxamine versus imipramine. Int Clin Psychopharm 9: 3-12.

Kessler RC, Borges G, Walters EE (1999). Prevalence of and risk factors for lifetime suicide attempts in the National Comorbidity Survey. Arch Gen Psychiatry 56: 617-626.

Khan A, Leventhal RM, Khan SR, Brown WA (2002). Severity of depression and response to antidepressants and placebo: an analysis of the Food and Drug Administration Database. J Clin Psychopharmacol 22: 40-45.

Kirsch I, Deacon BJ, Huedo-Medina TB, Scoboria A, Moore TJ, Johnson BT (2008). Initial severity and antidepressant benefits: a meta-analysis of data submitted to the Food and Drug Administration. PLoS Med 5: 260-268.

Lapierre YD (1991). Controlling acute episodes of depression. Int Clin Psychopharm 6: 23-35.

Mahapatra SN, Hackett D (1997). A randomised, double-blind, parallel-group comparison of venlafaxine and dothiepin in geriatric patients with major depression. Int J Clin Pract 51: 209-213.

Mann JJ (2003). Neurobiology of suicidal behaviour. Nat Rev Neurosci 4: 819-828.

Mann JJ, Apter A, Bertolote J, Beautrais A, Currier D, Haas A et al (2005). Suicide prevention strategies: a systematic review. J Am Med Assoc 294: 2064-2074.

Mann JJ, Waternaux C, Haas GL, Malone KM (1999). Towards a clinical model of suicidal behavior in psychiatric patients. Am J Psychiatry 156: 181-189.

Marchesi C, Ceccherininelli A, Rossi A, Maggini C (1998). Is anxious-agitated major depression responsive to fluoxetine? A double- blind comparison with amitriptyline. Pharmacopsychiatry 31: $216-221$.

Meyer RE, Salzman C, Youngstrom EA, Clayton PJ, Goodwin FK, Mann JJ et al (2010). Suicidality and risk of suicidedefinition, drug safety concerns, and a necessary target for drug development: a consensus statement. J Clin Psychiatry 71: e1-e21.

Möller HJ, Steinmeyer EM (1994). Are serotonergic reuptake inhibitors more potent in reducing suicidality? An empirical study on paroxetine. Eur Neuropsychopharmacol 4: 55-59.

Montgomery S, Cronholm B, Åsberg M, Montgomery DB (1978). Differential effects on suicidal ideation of mianserin, maprotiline and amitriptyline. Br J Clin Pharmac 5: 77S-80S.

Nock MK, Hwang I, Sampson NA, Kessler RC (2010). Mental disorders, comorbidity and suicidal behavior: results from the National Comorbidity Survey Replication. Mol Psychiatry 15: 868-876.

Oquendo MA, Galfalvy HC, Russo S, Ellis SP, Grunebaum MF, Burke AK et al (2004a). Prospective study of clinical predictors of suicidal acts after a major depressive episode in patients with major depressive disorder or bipolar disorder. Am J Psychiatry 161: 1433-1441.

Oquendo MA, Halberstam B, Mann JJ (2003). Risk factors for suicidal behavior: utility and limitations of research instruments. In: First MB (ed). Standardized Evaluation in Clinical Practice. APPI Press: Washington, DC. pp 103-130.

Oquendo MA, Stanley B, Ellis SP, Mann JJ (2004b). Protection of human subjects in intervention research for suicidal behavior. Am J Psychiatry 161: 1558-1563.

Owens MJ, Krulewicz S, Simon JS, Sheehan DV, Thase ME, Carpenter DJ et al (2008). Estimates of serotonin and norepinephrine transporter inhibition in depressed patients treated with paroxetine or venlafaxine. Neuropsychopharmacology 33: 3201-3212.

Pinheiro JC, Bates DM (2000). Generalized least squares. In: Mixed-Effects Models in S and S-PLUS. Springer: New York.

Placidi GPA, Oquendo MA, Malone KM, Brodsky B, Ellis SP, Mann JJ (2000). Anxiety in major depression: relationship to suicide attempts. Am J Psychiatry 157: 1614-1618. 
Rao CR, Wu Y (2001). On model selection. In: Lahiri P (ed). Model Selection. Institute of Mathematical Statistics: Beachwood, $\mathrm{OH}$. pp 1-64.

Rouillon F, Phillips R, Serrurier D, Ansart E, Gérard MJ (1989). Rechutes de dépression unipolaire et efficacité de la maprotiline. L'Encéphale XV: 527-534.

Sacchetti E, Vita A, Guarneri L, Cornacchia M (1991). The effectiveness of fluoxetine, clomipramine, nortriptyline and desipramine in major depressives with suicidal behaviour: preliminary findings. In: Cassano GB, Akiskal HS (eds). Serotonin-Related Psychiatric Syndromes: Clinical and Therapeutic Links: Proceedings of an international meeting held under the auspices of the Italian Society of Neurosciences and sponsored by Eli Lilly Italia SpA, held in Venice on 29-31 March 1990. Royal Society of Medicine Services: London. pp 47-53.

Saunders K, Simon G, Bush T, Grothaus L (1998). Assessing the feasibility of using computerized pharmacy refill data to monitor antidepressant treatment on a population basis: a comparison of automated and self-report data. J Clin Psychiatry 51: 883-890.
Schulz KF, Altman DG, Moher D (2010). CONSORT 2010 statement: updated guidelines for reporting parallel group randomised trials. Pharmacol Pharmacother 1: 100-107.

Spitzer RL, Williams JBW, Gibbon M, First MB (1990). Structured Clinical Interview for DSM-III-R/DSM-IV Patient Edition (SCID-P). American Psychiatric Press: Washington, DC.

Thase ME, Haight BR, Richard N, Rockett CB, Mitton M, Modell JG et al (2005). Remission rates following antidepressant therapy with bupropion or selective serotonin reuptake inhibitors: a meta-analysis of original data from 7 randomized controlled trials. J Clin Psychiatry 66: 974-981.

Tollefson GD, Greist JH, Jefferson JW, Heiligenstein JH, Sayler ME, Tollefson SL et al (1994). Is baseline agitation a relative contraindication for a selective serotonin reuptake inhibitor: a comparative trial of fluoxetine versus imipramine. $J$ Clin Psychopharmacol 14: 385-391.

Vinar O (1971). Scale for rating treatment emergent symptoms in psychiatry DVP. Act Nerv Super (Praha) 13: 238-240.

Wojnar M, Ilgen MA, Wojnar J, McCammon RJ, Valenstein M, Brower KJ (2009). Sleep problems and suicidality in the National Comorbidity Survey Replication. J Psychiat Res 43: 526-531. 